\title{
Assessing palliative care knowledge in a public health hospital
}

\begin{abstract}
Introduction: Palliative Care is a way to promote quality of life and comfort to patients facing life-threatening, facing this a growing need for this kind of care. Seen the growing needs, health policies should be developed to improve this kind of care in public health systems.

Methods: Retrospective data were collected from all medical records. Were assessed medical records from patients admitted in the Medical Clinic ward or ICU between September 2018 and December 2018 and who was at palliative care regardless of the reason.

Results: Were assessed 17 medical records of patients who had the Palliative Care installed during the hospitalization. The mean age was $71( \pm 20,3)$ and $23,5 \%$ of these patients were female. We can see poor knowledge facing the absence of more than half categories of therapeutics decision, more than $30 \%$ of all Edmonton Scale Symptom Assessment categories, and more than $29 \%$ of all functional evaluation categories.

Conclusion: Palliative Care still needs to be linked to public and universal health system with policies that encourage knowledge improvement and creating a Palliative Care teams to provide a better care and an end-of-life without suffering.
\end{abstract}

Keywords: palliative care, palliative medicine, health knowledge, attitudes, practice; medical records
Volume 5 Issue I - 2020

\author{
Bruno Bastos Godoi,, ${ }^{1,4}$ Luiza Vilas Boas \\ Freitas, ' Alice Assis Chaves,' Barbara \\ Machado Alfradique,' Isabella Ferreira \\ Brugiolo,' Maria Fernanda Nobre Leão, ${ }^{2}$ \\ Giovana Amaral Cordeiro, ${ }^{3,4}$ Fabiana Souza \\ Máximo Pereira ${ }^{3,4}$ \\ 'Student, Faculty of Medicine, Federal University of \\ Jequitinhonha and Mucuri Valleys, Brazil \\ ${ }^{2}$ Medical Clinic Resident, Faculty of Medicine, Federal University \\ of Jequitinhonha and Mucuri Valleys, Brazil \\ ${ }^{3}$ Professor, Faculty of Medicine, Federal University of \\ Jequitinhonha and Mucuri Valleys, Brazil \\ ${ }^{4}$ Palliative Care Team, Santa Casa de Caridade, Brazil
}

Correspondence: Bruno Bastos Godoi, Faculty of Medicine, Palliative Care Team, Federal University of Jequitinhonha's 'Valley and Mucuri, Santa Casa de Caridade, Diamantina/MG, Brazil,Tel +55(31)9868625II, Email bastosgodo@gmail.com

Received: December 14, 2019 | Published: February 25, 2020

\section{Introduction}

Palliative Care (PC) is a multi-professional service that intends to improve quality of life of patients and their families facing some problems without known or effective treatment at the illness stage. ${ }^{1}$

The World Health Organization (WHO) defines PC as a way to promote quality of life and comfort to patients facing life-threatening, and can be applied from illness onset with therapies aimed at controlling diseases, through actions to minimize some symptoms, as pain or dysphagia. ${ }^{2-4}$

There is a growing number of patients with chronic diseases, who need intensive care or even PC to get a sense of well-being at endof-life. Moreover, with demographic and epidemiological transition, the number of patients with cancer and noncommunicable diseases are higher than others decades. So, this shows the unmet necessity of developing PC services linked to public health systems. ${ }^{2,3,5}$

Seen the growing needs for PC, health policies should be developed to improve this kind of care in public health systems. Besides the policy development, it is necessary to achieve the health professional knowledge (mainly physicians and nurses), specifically those who are closely linked to patients in PC. So, this knowledge improvement should demonstrate a higher satisfaction of the patient and their family, and also enrich the care of these patients and mainly with the symptoms control. ${ }^{4,6,7}$ There are more than 400,000 PC workers worldwide, who needs to face end-life issues and patients with spiritual, physical and other necessities. With this, those professionals needs a great capacitation to face this diary deals with different patients.
Moreover, PC caregivers must have some skills in end-of-life care: bad news communication; symptom assessment; examination and identification of physical signs. So, corroborating with information aforementioned, PC caregivers should pass through periodic training programs to learn and remember vital concepts about PC care, such as: communication strategies; caregiver support; psychosocial care, pain management; other symptoms management and ethical/spiritual issues. $^{8}$

An important point that needs to be cited is that medical records resume all the approaches made by the PC team or others health professional. So, it is very important to write all the needs of patient, the approaches to control symptoms and other disease consequences. With this, medical records may be used to evaluate the quality of care of health systems and the professionals' attitudes. ${ }^{9-11}$

This study aimed to verify the quality of assessment at patients in PC being evaluated by professional without a PC specialization. The evaluation was made by searching some indispensable information in medical records of patients in PC advocated by Brazilian National Academy of Palliative Care.

\section{Methods}

\section{Study site characterizations}

The study as a whole were conducted in the city of Diamantina, which is a Brazilian municipality in the state of Minas Gerais located in the Jequitinhonha Mesoregion. Its population estimated in 2017 by the Brazilian Institute of Geography and Statistics was 48230 inhabitants. More specifically, we will work at the Santa Casa de 
Caridade de Diamantina/MG, a philanthropic hospital that was created in the year 1780, and today is a reference for several municipalities totalizing about 102 thousand inhabitants.

\section{Data collection from medical records}

Retrospective data were collected from all medical records of patients admitted to the Santa Casa de Caridade de Diamantina/MG at the Medical Clinic ward and the Intensive Care Unit (ICU) between September 2018 and December 2018. This study was approved by Ethical Committee Research of Federal University of Jequitinhonha's Valleys and Mucuri.

The collected data were in accordance of Brazilian National Academy of Palliative Care, that advocates some information that should be described in medical records of PC patients:

\section{Functional evaluation;}

2. Edmonton Symptom Assessment Scale;

3. Physical Exam;

4. Therapeutic Decisions;

5. Complementary Exams;

6. Specialist Evaluation;

7. Plan of Care;

8. Prognostic.

\section{Inclusion criteria for data collection in medical records}

Patients admitted to the Santa Casa de Caridade de Diamantina/ MG in the Medical Clinic ward or ICU between September 2018 and December 2018 and who was at palliative care with a professional non-specialist at Palliative Care.

\section{Exclusion criteria for data collection in medical records}

Patients admitted to other health institutions in the municipality of Diamantina/MG and those admitted to the Santa Casa de Caridade de Diamantina/MG assisted by a PC specialist caregiver.

\section{Statistical analysis}

Microsoft Excel ${ }^{\circledR}$ software was used to structure the database, organizing and grouping the information necessary for the research objectives. Then, descriptive analysis was made to compare the presence (or absence) of each information that should be in medical records of $\mathrm{PC}$ patients.

\section{Results}

Were assessed 17 medical records of patients who had the Palliative Care installed during the hospitalization. The mean age was $71( \pm 20,3)$. Some information was assessed and the percentage of the absence of this is shown in Table 1. Moreover, all of the medical records have the information about complementary exams, the absence rate of records about specialist's evaluation was $32,3 \%$, and about plan care and prognostic was $35,2 \%$.

The functional evaluation was divided into five subclasses: ambulation, disease activity and evidence, self-care, ingestion, and level of consciousness. Whose have the rate of absence shown in Figure 1.
Table I Mean rate of absence of some critical information to palliative care patient

\begin{tabular}{|c|c|}
\hline Functional evaluation & $88,2 \%(S D \pm 33,1)$ \\
\hline Edmonton Symptom Assessment Scale & $64,7 \%(S D \pm 22,6)$ \\
\hline Physical Exam & $17,6 \%(S D \pm 0)$ \\
\hline Therapeutic Decisions & $82,3 \%(S D \pm 42,6 \%)$ \\
\hline Complementary Exams & $0 \%$ \\
\hline Specialist Evaluation & $32,3 \%$ \\
\hline Plan of Care & $35,2 \%$ \\
\hline Prognostic & $35,2 \%$ \\
\hline
\end{tabular}

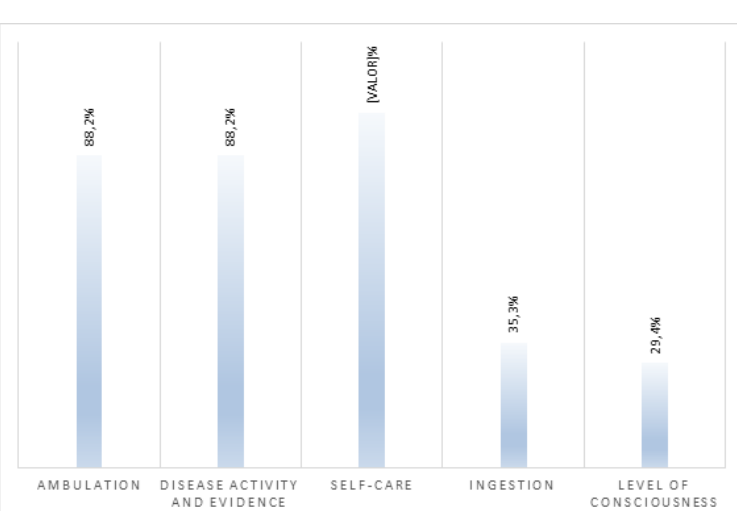

Figure I Subclasses of functional evaluation and rates of absence in medical records.

The Edmonton Scale Symptom Assessment was divided into nine subclasses: pain, tiredness, nausea, depression, anxiety, somnolence, appetite, shortness of breath, and sense of well-being. Whose have the rate of absence shown in Figure 2.

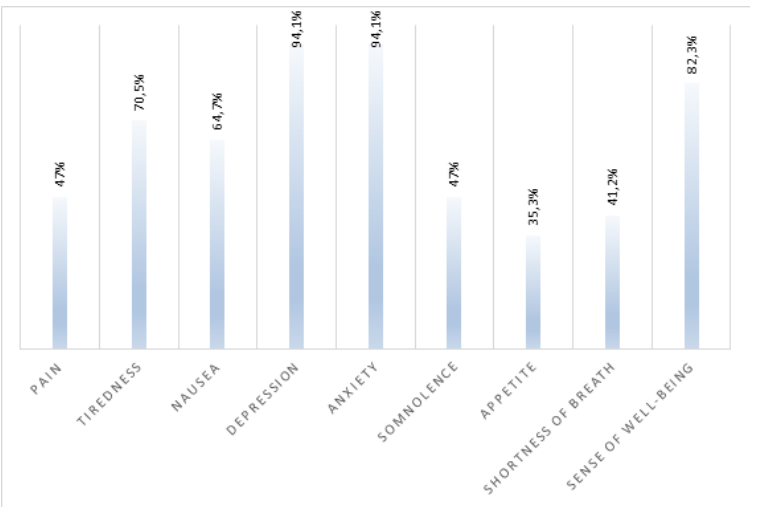

Figure 2 Subclasses of edmonton scale symptom assessment and rates of absence in medical records.

Also, the physical exam was divided into four categories: cardiac frequency, respiratory frequency, blood pressure, and Glasgow Coma Scale. Whose have the rate of absence shown in Figure 3.

Therapeutic decisions were divided into eight categories: medicines and doses, initiation or suspense of measures, exams and assessment request, needs of physic interventions, social needs, interventions performed or request with the family, spiritual needs, and expected effect of actions. Whose have the rate of absence shown in Figure 4. 


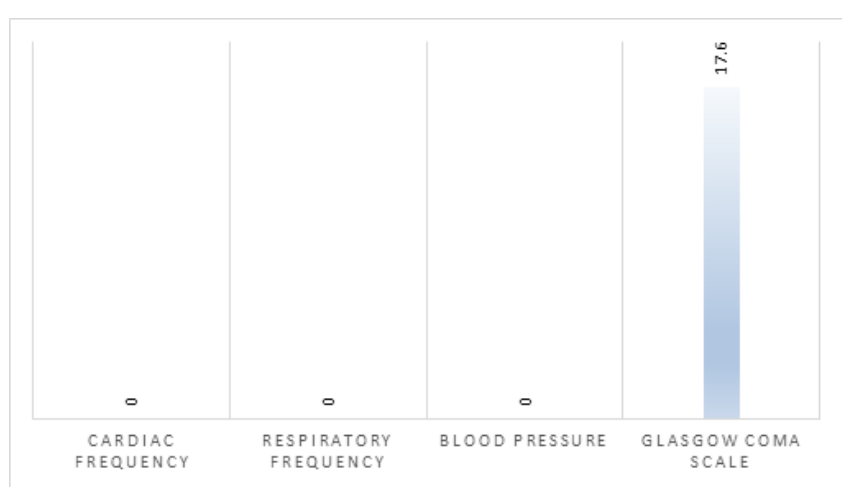

Figure 3 Categories of physical exam and rates of absence in medical records.

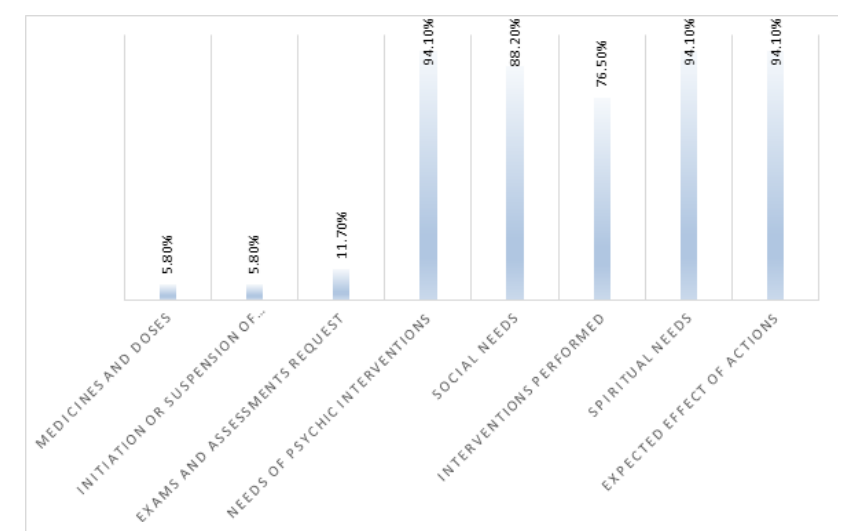

Figure 4 Categories of therapeutic decisions and rates of absence in medical records.

\section{Discussion}

The needs of PC are a growing necessity, mainly in recent years due of the demographic and epidemiological transition. Seen this, health system has to adapt to develop excellence PC team with empowered professionals. ${ }^{12}$ Moreover, the registration in medical records is quite importance to show knowledge and quality on assistance of PC patients. Nevertheless, even though this ascending needs for PC, this kind of care is still incipient and, when assessing the quality of care to these patients at public hospitals without PC team or specialists, it can be noted that a lot of essential evaluation at end-of-life are set aside due of poor knowledge. .11,13-15 $^{8}$

Although it is known that PC knowledge is very important for all health professionals nowadays, but no researchers found that aims to evaluate the medical records and the practices of non-PC specialists ${ }^{16}$. With this, there is no scientific evidence comparing daily practice, knowledge, performance and quality of medical records of those professionals (mainly physicians and nurses) specialists in PC and those non-specialists in PC. ${ }^{11}$ So, there are no scientific data to corroborate or refuge the results founds at this study, but what we can show is that the medical records are not in accordance with the statement of National Academy of Palliative Care. Moreover, it can be shown that even data about physical exam are absence, like Glasgow Coma Scale (a rate of absence around 17\%), which is an information quite importance to evaluate the patient's response to the treatment instituted.
Seen this poor scientific evidence about medical records in PC, can be found some researches about self-confidence and knowledge about PC in most professional of diverse sectors from the public system. ${ }^{8,9,11-13,17-19}$ According to Krautheim et al. ${ }^{17}$ more than half of the ICU physicians said that was "rather confident" or "confident", but the average of correct answers in the knowledge test was 55\%. Seen this, they have showed that the correlation about self-confidence and knowledge was poor $(r=0.104, p=0.230)$. Moreover, Snyder et al. ${ }^{9}$ showed an overview at primary care, which a rate of $20 \%$ of the professionals said that $\mathrm{PC}$ in only applicable if patient have 6 months or less of life. But $97,5 \%$ felt comfortable to discuss about advance care planning. Besides that, there was no correlation between physicians' comfort on discussing advanced care planning and the number of referrals to PC or hospice ( $r=0.142, p=0.132$ and $r=0$ $.021, p=0.821$, respectively). With this, can be resumed that there is a disparity about what the physicians feel about their knowledge and what they really do on daily practice at PC. So, this can result on poor care of patients in end-of-life, because the high self-confidence of the professionals but low knowledge about PC and symptoms control.

This mismatch between self-confidence and knowledge in PC health professionals can refer to the knowledge worked in the faculties, where PC in not a priority and in some countries even don't makes part of the curriculum. ${ }^{15,20,21}$ According to Mutto et al. ${ }^{21}$ students that have passed through an elective subject about PC had higher knowledge in this kind of patient care and was more confident on treating patients in end-of-life, like communicating bad news and controlling symptoms. Von Gunten et al..$^{20}$ assessed the impact of including PC as a subject of medical curriculum. They showed an impressive improvement on knowledge in PC with 23\% improvement in knowledge, $56 \%$ in selfreported competence and $29,5 \%$ decrease in self-reported concern. Facing this scenario, is notorious that both students and professionals have no correlation between self-reported and knowledge. In a point of view, this can be good to face daily problems and mainly the death of patients, in other way we can see that there is no sufficient knowledge to treat patients as it should. Therefore, evaluating the medical records, we can see poor knowledge facing the absence of more than half categories of therapeutics decision, more than $30 \%$ of all Edmonton Scale Symptom Assessment categories, and more than $29 \%$ of all functional evaluation categories.

Besides that, this study has some limitations. We cannot evaluate the self-reported of health professionals or the experience in PC. Moreover, it is a retrospective study, so could have some mistake writing on the medical records or some data could be lost. Finally, this study didn't aim to evaluate if patients were available to PC or not, this information could change some daily practice and medical records.

\section{Conclusion}

In fact, Palliative Care is a growing kind of care, principally because the demographic and epidemiological transition, adding this an ascending rate of chronic diseases and cancer. Although it is known that $\mathrm{PC}$ is quite important to patients in end-of-life, the knowledge of health professionals doesn't accomplish this social and health need.

Therefore, PC caregivers should pass through periodic trainings to accurate PC knowledge and skills needed in order to face daily issues in PC assessment.

Given the above, PC still needs to be linked to public and universal 
health system with policies that encourage knowledge improvement and creating PC teams to provide a better care and an end-of-life without suffering.

\section{Funding}

None.

\section{Acknowledgments}

None.

\section{Conflicts of interest}

The authors declare no conflict of interest.

\section{References}

1. Godoi BB, Boas LV, Chaves AA, et al. Palliative care and public health an issue to be held. MOJ Gerontol Geriatr. 2020;5(1):23-25.

2. Lopez AD, Murray CCJL. The global burden of disease, 1990-2020 Nature Medicine. 1998;4:1241-1243.

3. Murray CJL, Lopez AD. Alternative projections of mortality and disability by cause 1990-2020: global burden of disease study. Lancet. 1997;349(9064):1498-504.

4. Callaway MV, Connor SR, Foley KM. World health organization public health model: a roadmap for palliative care development. J Pain Symptom Manage. 2018;55(2):S6-S13.

5. Dzingina MD, Higginson IJ. Public health and palliative care in 2015 WB. Saunders; Clinics in Geriatric Medicine. 2015;31:253-63.

6. Scaccabarozzi G, Limonta F, Amodio E. Hospital, local palliative care network and public health: how do they involve terminally ill patients? Eur J Public Health. 2017;27(1):25-30

7. Beng TS, Guan NC, Jane LE, et al. Health care interactional suffering in palliative care. Am J Hosp Palliat Med. 2014;31(3):307-14.

8. Al-Kindi SG, Zeinah GFA, Hassan AA. Palliative care knowledge and attitudes among oncology nurses in Qatar. Am J Hosp Palliat Med. 2014;31(5):469-474.

9. Snyder S, Hazelett S, Allen K, et al. Physician knowledge, attitude, and experience with advance care planning, palliative care, and hospice: results of a primary care survey. Am J Hosp Palliat Med. 2013;30(5):419424 .
10. Davies JM, Gao W, Sleeman KE, et al. Using routine data to improve palliative and end of life care. BMJ Support Palliat Care. 2016;6(3):257262.

11. Davison SN, Jhangri GS, Koffman J. Knowledge of and attitudes towards palliative care and hospice services among patients with advanced chronic kidney disease. BMJ Support Palliat Care. 2016;6(1):66-74.

12. Cartwright CM, White BP, Willmott L, et al. Palliative care and other physicians' knowledge, attitudes and practice relating to the law on withholding/withdrawing life-sustaining treatment: Survey results. Palliat Med. 2016;30(2):171-179.

13. Chover-Sierra E, Martínez-Sabater A, Lapeña-Moñux Y. Knowledge in palliative care of nursing professionals at a Spanish hospital. Rev Lat Am Enfermagem. 2017;25(0).

14. Kozlov E, Carpenter BD, Rodebaugh TL. Development and validation of the palliative care knowledge scale (PaCKS). Palliat Support Care. 2017;15(5):524-34

15. Nakazawa Y, Yamamoto R, Kato M, et al. Improved knowledge of and difficulties in palliative care among physicians during 2008 and 2015 in Japan: Association with a nationwide palliative care education program. Cancer. 2018;124(3):626-635.

16. Da Silva MM, Büscher A, Moreira MC. Palliative cancer care in Brazil: the perspective of nurses and physicians. Cancer Nurs. 2017;40(4):289296.

17. Krautheim V, Schmitz A, Benze G, et al. Self-confidence and knowledge of German ICU physicians in palliative care - A multicentre prospective study. BMC Palliat Care. 2017;16(1):1-8.

18. Khraisat OM, Hamdan M, Ghazzawwi M. Palliative care issues and challenges in saudi arabia: Knowledge assessment among nursing students. J Palliat Care. 2017;32(3-4):121-126.

19. Kizawa Y, Morita T, Miyashita M, et al. Improvements in physicians' knowledge, difficulties and self-reported practice after a regional palliative care program. J Pain Symptom Manage. 2015;50(2):232-240.

20. Von Gunten CF, Mullan P, Nelesen RA, et al. Development and evaluation of a palliative medicine curriculum for third-year medical students. $J$ Palliat Med. 2012;15(11):1198-1217.

21. Mutto EM ari, Bunge S, Vignaroli E, et al. Medical students' palliative care education in a Latin American university: a three-year experience at Austral University in Buenos Aires, Argentina. J Palliat Med. 2014;17(10):1137-1142. 